\title{
USO IRRACIONAL DOS MEDICAMENTOS FITOTERÁPICOS: UMA REVISÃO DA LITERATURA
}

\author{
IRRATIONAL USE OF MEDICINES PHYTOTHERAPY: A LITERATURE REVIEW
}

\section{USO IRRACIONAL DE LOS MEDICAMENTOS FITOTERÁPICOS: UNA REVISIÓN DE LA LITERATURA}

Lindiely Cabral do Monte ${ }^{1}$

Rafael Rodrigues Gomides ${ }^{2}$

RESUMO: Objetivo: A presente revisão apresentou o uso irracional dos medicamentos fitoterápicos. Métodos: Revisão de literatura a partir de artigos científicos das bases LILACS, Scielo e DeCS. Foram utilizados descritores específicos para obtenção de trabalhos publicados entre os anos 2013 e 2020. Foram incluídos os estudos com base nas características do uso irracional de medicamentos fitoterápicos e excluídos os estudos voltados a uso racional, remédios fitoterápicos e droga vegetal. Resultados: Foram pesquisados 20 trabalhos nas bases de dados, após serem analisados sobre o uso irracional de medicamentos fitoterápicos após seguir os critérios de inclusão e de exclusão foram utilizados efetivamente para a revisão io estudos, assim três artigos foram excluídos por apresentarem-se repetidos nas bases de dados e outros sete artigos excluídos por tratar-se de revisões integrativas e resenhas de livro que não respondessem o estudo em questão. Considerações finais: $\mathrm{O}$ uso irracional de drogas é um dos problemas de saúde global mais importante e a situação é pior no domínio dos medicamentos fitoterápicos. As intervenções para combater o uso irracional de medicamentos fitoterápicos e a promoção de uma abordagem mais racional requerem motivação e adesão a diretrizes clínicas rígidas por parte dos profissionais e conscientização do público em geral.

Palavras-chave: Medicamentos Fitoterápicos. Uso Irracional. Fitoterapia.

ABSTRACT: Objective: The present review presented the irrational use of medicines phytotherapy. Methods: Literature review based on scientific articles from LILACS, Scielo and DeCS databases. Specific descriptors were used to obtain works published between the years 2013 and 2020. Studies based on the characteristics of irrational use of medicines phytotherapy were

\footnotetext{
${ }^{1}$ Discente do curso de Farmácia da Faculdade de Quatro Marcos (UNIBRAS), São José dos Quatro Marcos-MT. Email: lindaellycabral@gmail.com.

${ }^{2}$ Docente Mestre em Farmácia Profissional da Faculdade de Quatro Marcos (UNIBRAS), São José dos Quatro Marcos-MT.*E-mail: rafael_sceu@hotmail.com.
} 
included and studies focused on rational use, phytotherapy medicines and plant drugs were excluded. Results: Twenty studies were searched in the databases, after being analyzed on the irrational use of medicines phytotherapy after following the inclusion and exclusion criteria,ro studies, thus three articles were excluded because they were repeated in the databases and another seven articles were excluded because they were integrative reviews and book reviews that did not answer the study in question. Conclusion: Irrational drug use is one of the most important global health problems and the situation is worse in the field of medicines phytotherapy. Interventions to combat the irrational use of medicines phytotherapy and the promotion of a more rational approach require motivation and adherence to strict clinical guidelines by professionals and awareness of the general public.

Keywords: Medicines Phytotherapy. Irrational Use. Phytotherapy.

RESUMEN: Objetivo: La presente revisión presentó el uso irracional de los medicamentos fitoterápicos. Métodos: Revisión de literatura basada en artículos científicos de las bases de datos LILACS, Scielo y DeCS. Se utilizaron descriptores específicos para la obtención de trabajos publicados entre los años 2013 y 2020. Se incluyeron estudios basados en las características del uso irracional de los medicamentos fitoterápicos y se excluyeron los estudios enfocados al uso racional, medicamentos herbarios y medicamentos vegetales.. Resultados: Se buscaron 20 estudios en las bases de datos, luego de ser analizados sobre el uso irracional de las medicinas a base de hierbas luego de seguir los criterios de inclusión y exclusión, se utilizaron efectivamente ro estudios para la revisión, por lo que se excluyeron tres artículos por repetirse en las bases de datos. Se excluyeron otros siete artículos porque son reseñas integradoras y reseñas de libros que no respondieron al estudio en cuestión. Conclusión: El uso irracional de drogas es uno de los problemas de salud mundial más importantes y la situación es peor en el campo de las medicinas a base de hierbas. Las intervenciones para combatir el uso irracional de los medicamentos a base de hierbas y la promoción de un enfoque más racional requieren motivación y adherencia a estrictas guías clínicas por parte de los profesionales y concienciación del público en general.

Palabras clave: Medicamentos Fitoterápicos. Uso Irracional. Fitoterapia.

\section{INTRODUÇÃO}

O uso de medicamentos fitoterápicos, fitonutrientes ou nutracêuticos continua a se expandir rapidamente em todo o mundo, com muitas pessoas agora recorrendo a esses produtos para o tratamento de vários desafios de saúde em diferentes ambientes nacionais de saúde. A última década testemunhou um tremendo aumento na aceitação e no interesse público pelas terapias naturais, tanto nos países em desenvolvimento quanto nos desenvolvidos, com esses remédios fitoterápicos disponíveis não apenas em drogarias, mas agora também em lojas de alimentos e supermercados (KLEIN T, et al, 2019). 
É de extrema importância ter em mente que planta medicinal e fitoterápicos não são sinônimos. De acordo com Fernandes TM (2014) as plantas medicinais são utilizadas para fins terapêuticos e podem ser utilizadas de diferentes formas, como extrato líquido, xarope, inaladores e óleos.

Segundo Almeida MZ (2013) os medicamentos fitoterápicos são, portanto, frequentemente vistos como uma abordagem equilibrada e moderada para a cura e os indivíduos que os usam como remédios caseiros e medicamentos sem receita gastam uma grande quantia em produtos fitoterápicos. Isso explica em parte o motivo pelo qual as vendas de medicamentos fitoterápicos estão crescendo e representa uma proporção substancial do mercado global de medicamentos.

De acordo com Schoaba (2018) como o uso global de produtos fitoterápicos continua a crescer e muitos outros produtos novos são introduzidos no mercado, as questões de saúde pública e as preocupações em torno de sua segurança também são cada vez mais reconhecidas. Embora alguns medicamentos fitoterápicos tenham potencial promissor e sejam amplamente utilizados, muitos deles permanecem não testados e seu uso também não monitorado, tornando o conhecimento de seus potenciais efeitos adversos muito limitado e a identificação das terapias mais seguras e eficazes, bem como a promoção de seu uso racional, mais difícil.

Também é de conhecimento comum que a segurança da maioria dos produtos fitoterápicos é ainda mais comprometida pela falta de controles de qualidade adequados, rotulagem inadequada e ausência de informações adequadas do paciente. Tornou-se essencial, portanto, fornecer ao público em geral, incluindo os profissionais de saúde, informações adequadas para facilitar a melhor compreensão dos riscos associados ao uso desses produtos e para garantir que todos os medicamentos são seguros e de qualidade adequada (MACEDO, 2016).

Dentro do contexto apresentado, o presente trabalho buscará responder qual a consequência do uso irracional dos medicamentos fitoterápicos?

\section{MÉTODOS}

As buscas dos artigos foram realizadas 2013 a 2020, utilizando as seguintes bases de dados indexados: LILACS (Literatura Latino-Americana e do Caribe em Ciências da Saúde); Scientific Electronic Library Online (SciELO), com uso dos Descritores em Ciência da Saúde (DeCS): Medicamentos Fitoterápicos. Uso racional. Fitoterapia. 
FIGURA r: FLUXOGRAMA DA BUSCA DOS ARTIGOS.

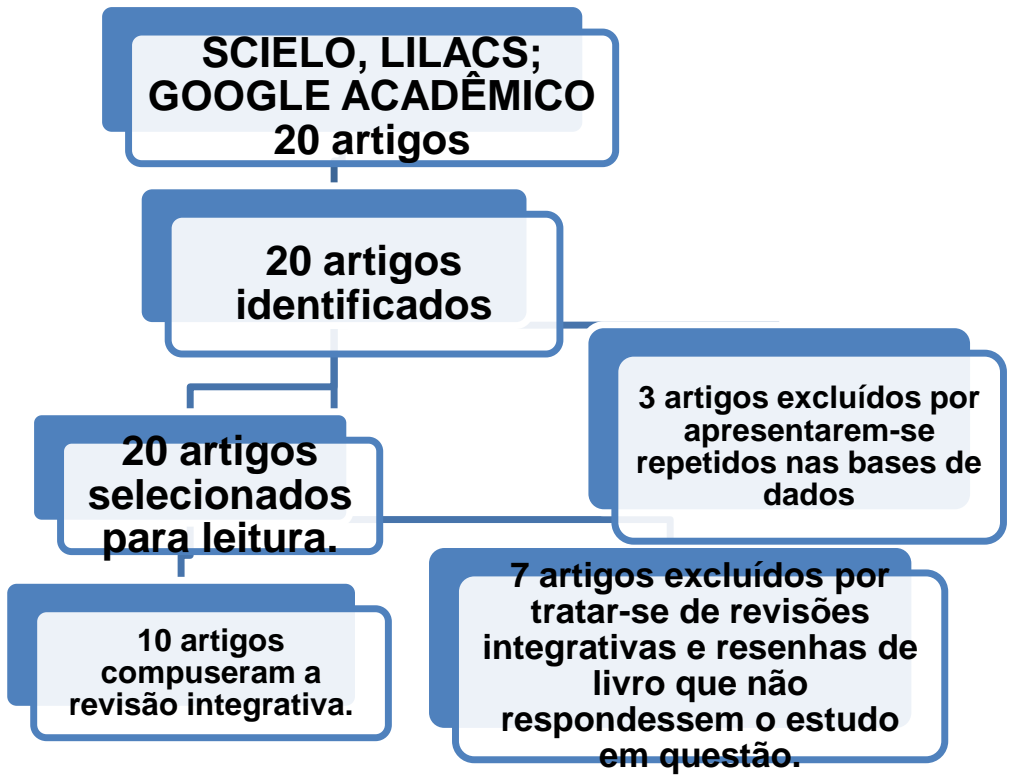

Fonte: Elaborado pelo autor.

Para a seleção do material foram considerados critérios de inclusão biografias que abordassem o uso irracional dos medicamentos fitoterápicos, sendo excluídos o uso racional, remédios fitoterápicos e droga vegetal.

\section{RESULTADOS}

Segundo Virgílio e Marques (2014), a lei que rege o registro de medicamentos fitoterápicos no Brasil costuma seguir a lei utilizada na Alemanha, que combina evidências científicas (pré-clínica, toxicológica e clínica) com o conhecimento da população milenar por meio de plantas medicinais.

Segundo Oshiro (2016), as atividades de vigilância sanitária foram iniciadas no Brasil em I93ı. O Decreto no 19606 é regulamentado pelo Decreto $n^{\circ}$ 20377, que presta serviços jurídicos para a indústria farmacêutica. No que diz respeito às plantas medicinais, o decreto inclui "as transações diretas com os consumidores de plantas medicinais para fins terapêuticos" no âmbito das atribuições do farmacêutico.

Agora, na forma personalizada e independente do Ministério da Educação, assinou contrato com o Ministério da Saúde em 1953, com foco em sua área de atuação. Em 1959, foi publicada a 
segunda edição da "Farmacopéia Brasileira" e embora os insumos vegetais tivessem importância secundária, as especificações das matérias-primas farmacêuticas foram atualizadas (MINISTÉRIO DA SAÚdE, 2016).

Segundo Virgílio e Marques (2014), na década de 1960, o Decreto no 10/30/1967 no 22, originado da National Drug Inspection Administration, estabeleceu as regras para o uso de preparações fitoterápicas e propôs conteúdo inédito a esse respeito. Seus in artigos incluem a definição de produtos fitoterápicos, a obrigação do fabricante de fornecer dados técnicos sobre medicamentos, preparados fitoterápicos, suas formulações, indicações terapêuticas, rótulos e bulas.

Segundo Macedo (2016), na década de 1970, foi promulgada a Lei no 5.991 em 17 de dezembro de 1973, que previa o controle sanitário do comércio de medicamentos e produtos derivados. Essa lei estipula que a distribuição de ervas se limita às farmácias e lojas de produtos naturais, mas com embalagem adequada e "classificação vegetal". Atenção deve ser dada ao uso indevido do termo "classificação botânica" ao invés de "identificação".

De acordo com Oshiro (2016), a lei básica do Brasil sobre vigilância sanitária é a Lei no 6.36o, de 23 de setembro de 1976, que dispõe sobre o controle de medicamentos, insumos, artigos correlatos, cosméticos, desinfetantes e outros produtos. A lei visa "garantir a identidade, qualidade, atividade, pureza e segurança dos produtos sujeitos à fiscalização sanitária" e utiliza "registro" em vez de "licença".

De acordo com Almeida (2013), o Ministério da Saúde realizou reformas administrativas internas. Assim, o Serviço Nacional de Fiscalização de Medicina e Farmácia (SNFMF) original tornou-se uma Secretaria Nacional de Vigilância Sanitária composta por departamentos com capacidade de controlar, avaliar, coordenar e fiscalizar as atividades relacionadas.

Segundo Macedo (2016), o Ministério da Saúde foi afetado pela diretriz anterior da Organização Mundial da Saúde há alguns anos e convocou uma comissão de especialistas em 1994 para avaliar o estado da fitoterapia no país. A proposta revisada foi incorporada à Portaria no 6 emitida pela SVS em 1995, que finalizou as exigências legais para o registro de medicamentos fitoterápicos no Brasil.

Portanto, o Decreto no 6, de 31 de janeiro de 1995, define os produtos fitofarmacêuticos como "medicamentos processados que utilizam apenas materiais vegetais como matéria-prima e / ou 
preparados com botânicos. São elaborados para tratar, curar, aliviar, prevenir e diagnosticar doenças” e estipula os requisitos legais para medicamentos fitoterápicos registrados (FERNANDES, 2014).

A portaria também estipula outras disposições pertinentes, regras de produção e comercialização, o registro de novos medicamentos fitoterápicos e o registro de medicamentos fitoterápicos que tenham sido comercializados voltem a vigorar. Após a implementação, é necessária a melhoria de alguns itens, o que foi concluído na Portaria SVS (Secretaria de Vigilância Sanitária) no 1029/98 (SOUZA, et al, 2019).

Segundo Oshiro (2016), a Portaria SVS no $1029 / 98$ possui basicamente a mesma estrutura de sua antecessora, mantendo a mesma definição de fitoterápicos e os mesmos padrões de comprovação de eficácia, segurança e qualidade. Ela adiciona procedimentos de registro simplificados para produtos fitoterápicos tradicionais, que aparecem na lista de aprovados pela SVS e a estrutura da lista de produtos fitoterápicos tradicionais foi determinada no texto do decreto.

Como alternativa ao Decreto no o6/95, a Agência Nacional de Vigilância Sanitária (ANVISA) 769 do Ministério da Saúde editou a última regulamentação $\operatorname{RDC~} \mathrm{n}^{\mathrm{O}}{ }_{17}$ (24/02/2000) emitida pelo país, que regulamenta os produtos fitoterápicos. Define qualquer medicamento obtido e elaborado por meios técnicos e como produto fitoterápico, utiliza integralmente materiais vegetais ativos para fins preventivos, terapêuticos ou diagnósticos, benéficos para os usuários e caracterizados pela eficácia e utilização. Portanto, substâncias ativas isoladas, de origem vegetal ou não, não podem ser adicionadas a esta formulação (SILVA, ALMEIDA E ROCHA, 20I4).

\section{I Políticas Públicas Sobre Fitoterápicos No Brasil}

Para o uso correto dos fitoterápicos, políticas e acordos nacionais e internacionais foram formulados com base nos princípios de segurança, eficácia, qualidade e desenvolvimento ambiental sustentável. De acordo com Macedo (2016), com o desenvolvimento da medicina tradicional, informações importantes sobre a natureza e o uso de plantas medicinais para proteger a saúde foram perdidas ao longo dos anos e nos últimos anos, tem havido grande interesse em resgatar esse conhecimento empírico e transformá-lo em conhecimento científico, por meio da 
implementação de políticas públicas e do fomento à pesquisa para torná-la uma planta medicinal utilizável por toda a população brasileira.

De acordo com Almeida (2013), nos últimos dez anos após a edição do Decreto no 971 (3 de maio de 2006) e do Decreto no 5813 (22 de junho de 2006), as políticas públicas relacionadas às plantas medicinais e fitoterápicas têm sido desenvolvidas. Envolvem a Política Nacional de Práticas Integradas e Complementares (PNPIC) e a Política Nacional de Plantas Medicinais e Fitoterápicas.

Segundo o Ministério da Saúde (2016), a construção da Política Nacional de Práticas Integrais e Complementares (PNPIC) no SUS começa a partir do cumprimento das diretrizes e recomendações de diversas Conferências Nacionais de Saúde e das recomendações da Organização Mundial da Saúde (OMS).

Esses sistemas e recursos envolvem métodos que buscam estimular os mecanismos naturais de prevenção de agravos e restauração da saúde por meio de tecnologias eficazes e seguras, com foco no acolhimento, escuta, estabelecimento de vínculo terapêutico e integração das pessoas com o meio ambiente e a sociedade (OSHIRO, 2016).

Essa política é considerada mais uma etapa do processo de implantação do Sistema Único de Saúde (SUS) na atenção básica. Atende às necessidades da Organização Mundial da Saúde (OMS) e da população brasileira, bem como a necessidade de padronizar e harmonizar essas práticas nas redes públicas de saúde. Esta política fornece diretrizes e ações para a inserção de serviços e produtos relacionados à medicina chinesa / acupuntura, homeopatia, plantas medicinais e ervas (VIRGÍLIO E MARQUES, 2014).

Portanto, segundo Rossato, et al (2013), as diretrizes consideradas no PNPIC regulamentam o uso e a fitoterapia das plantas medicinais chinesas do SUS. Esta proposta é baseada no modelo ocidental de fitoterapia, que é entendida como terapias caracterizadas pelo uso de plantas medicinais em diferentes formas de medicamentos, mesmo que utilizem fontes vegetais sem o uso de substâncias ativas isoladas, o método incentiva a comunidade ao desenvolvimento, solidariedade e participação social.

Essas diretrizes também consideram as responsabilidades dos entes federais, estaduais e municipais e estendem as opções de tratamento aos usuários do SUS em seus objetivos, garantindo 
o acesso a produtos e serviços fitoterápicos seguros, eficazes, eficientes e de qualidade. Basicamente, após a resolução do Ciplan (março de 1988), o sistema público de saúde do Brasil implementou algumas ações e planos de fitoterapia na década de 1980, que regulamentaram esses comportamentos nos serviços públicos. Desde então, alguns governos estaduais e municipais padronizaram e regulamentaram o uso de fitoterapia no SUS (OSHIRO, 2016).

De acordo com a discussão de Virgílio e Marques (2014), durante o desenvolvimento das diretrizes de plantas medicinais e fitoterápicas do SUS inseridas pela PNPIC, percebeu-se que é necessário formular uma política nacional que considere o desenvolvimento de toda a cadeia produtiva das plantas medicinais e fitoterápicas. Dentre os diversos fatores que comprovam a necessidade de formulação de políticas na área de plantas medicinais e fitoterápicas, um país oferece potencial e oportunidades para o desenvolvimento da indústria, como a rica biodiversidade e o desenvolvimento da tecnologia botânica brasileira.

Assim, em 22 de junho de 2006, foi aprovada a Política Nacional de Plantas Medicinais e Fitoterápicas, que estabelece diretrizes e prioridades para as ações dos diversos parceiros, com o objetivo geral de garantir o acesso seguro e o uso racional dos fitoterápicos à população brasileira. Portanto, o PNPMF implementou diretrizes de ação governamental na área de plantas medicinais e fitoterápicas (MINISTÉRIO DA SAÚDE, 2016).

Para o cumprimento dos objetivos desta política, foi aprovado o Decreto no 2.960 , em o9 de dezembro de 2008, que aprova o Programa Nacional de Plantas Medicinais e Fitoterápicas, que visa realizar ações importantes para melhorar o acesso das pessoas às plantas medicinais (OSHIRO, 2016).

Segundo o Ministério da Saúde (2016), os princípios norteadores do processo de formulação do Plano Nacional de Plantas Medicinais e Fitoterápicas são: ampliar o leque de opções de tratamento e melhorar a atenção à saúde dos usuários do Sistema Único de Saúde; uso sustentável da biodiversidade brasileira; avaliação; preservação dos conhecimentos tradicionais das comunidades indígenas; fortalecer a agricultura familiar; o desenvolvimento industrial e tecnológico; a inclusão social, reduzindo a desigualdade social e a participação pública e o controle social. 


\subsection{Histórico das legislações sobre medicamentos fitoterápicos}

De acordo com a legislação brasileira, os medicamentos podem ser manipulados ou industrializados e podem ser distribuídos para uso humano (regulamentado pela ANVISA) ou por veterinários (regulamentado pelo Ministério da Agricultura, Pecuária e Abastecimento) (ALMEIDA, 2013).

De acordo com Souza, et al (2019) o tratamento com fitoterápicos para humanos é realizado em uma farmácia de forma especializada e formal. Considerando que a tabela nacional contém apenas fórmulas para drogas sintéticas, atualmente não existe nenhuma fórmula fitoterápica. Para mudar esse quadro, a Farmacopéia Brasileira está preparando o Formulário Fitoterápico Brasileiro (FFB).

A manipulação de medicamentos é regulamentada pela norma RDC 67/2007, atualizada pela RDC $87 / 2008$, que define boas práticas para o manuseio da gestão da segurança pública $e$ preparação de oficinas para uso humano em farmácias. Os medicamentos manipulados são isentos de registro na Anvisa, e o controle de qualidade é feito internamente(SCHOABA,2018). Para compreensão e melhor esboço citamos a tabela or algumas das principais classes terapêuticas, e a nomenclatura botânica adaptado de Carvalho, et al (2008).

Tabela r: Classificação de acordo com a principal categoria terapêutica comprovada no registro.

CATEGORIA TERAPÊUTICA

Analgésicos contra enxaqueca

Analgésicos

Andrógeno

Ansioliticos simples

Antiagregante plaquetário

Antialérgicos

Antiarritmico

Antidepressivos

Antieméticos e antinauseantes

\section{NOMENCLATURA BOTÂNICA}

Tanacetum parthenium

Salix alba

Tribulus terretris

Valeriana officinalis, Piper methysticum, Passiflora incarnata, Melissa officinalis, Matricaria recutita

Ginkgo biloba

Glycyrrhiza glabra, Petasites hybridus

Crataegus oxyacantha

Hypericum perforatum

Zingiber officinale 
Antiespasmódico

Antihemorrodários (tópico)

Antilipêmicos

Antiinflamatórios (oral)

Antiinflamatórios (tópico)

Antiparasitários

Anti-sépticos urinários simples

Antiulcerosos

Antivaricosos de ação sistêmica, inclusive anti-
Atropa belladonna, Farmaria officinalis, Matricaria recutita, Melissa officinalis, Mentha piperita, Papayer sonniferum, Peumus boldus

Hamamelis virginiana

Allium sativum, Oryza sativa

Barago officinalis, Boswellia serrata, Cassia occidentalis, Harpagophytum procumbens, Ocnothera beinnis, Uncaria tomentosa

Calenduta officinalis, Capsicum annum, Cardia verbenácea, Matricaria recutita, Uncaria tomentosa

Mentha crispa

Arctostaphylus uva-ursi

Maytenus ilicifolia

Aesculus hippocastanum, Hamamelis virginiana, Melilotus officinalis, Ruscus aculeatus

hemorroidário

Assim, descrevemos os resultados encontrados após analises, em forma de quadro para facilitar compreensão do texto e assunto abordado logo abaixo:

\section{Quadro I: Resultados da análise de artigos.}

\section{Referências}

OSHIRO, Mariana Cardoso. A evolução do registro e prescrição de fitoterápicos no

Brasil sob a perspectiva legal e e sites oficiais. sanitária. Revista visa em debate: sociedade, ciência e tecnologia, Curitiba, v. 4, n. 2, p. 116-122, mar./2016. Disponível em: $10.22239 / 2317-269 X .00790$.

\section{Metodologia}

Pesquisa

qualitativa em

bases de dados

:

(n)


VIRGÍlIO, L.J. E MARQUES, L.C. Avaliação dos efeitos da qualitativo. Resolução RDC 17 sobre fitoterápicos de registros antigos. Revista Brasileira de Farmacognosia, Maringá, v. 4, n.1, p. 100-113, dez/2014. Disponível em: https://doi.org/10.1590/Soro2-

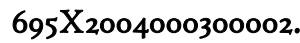

KLEIN et al. Fitoterápicos: um mercado promissor. Revista de Ciências Farmacêuticas Básica e Aplicada, Maringá, v. 30, n. 2, p. 241248, jan./2019.

escopo critérios para controle de qualidade, boas práticas de fabricação, validação de métodos analíticos, estabilidade e farmacovigilância.

Todos os nove
qualitativamente o medicamentos apresentaram mercado brasileiro de problemas na rotulagem e fitoterápicos a partir de bula, destacando se a falta das medicamentos seguintes informações: registrados mecanismos de ação do anteriormente à 1995 produto (I00\%), parte usada como expressão do $(78 \%)$, superdosagens $(67 \%)$, conjunto de produtos cuidados com crianças $e$ fitoterápicos antigos em idosos $(56 \%)$, cuidados de mercado. conservação (22\%) e riscos dos produtos (II\%). Em relação aos estudos de segurança e eficácia, apenas dois laboratórios (2/9) se posicionaram de maneira esclarecedora e informaram o andamento dos mesmos. Verifica-se, portanto, que os medicamentos de registro antigo, por diversos motivos, encontram-se fora dos padrões legais exigidos

Revisão Discutir a situação Bibliográfica. atual dos FTM e a seriedade que se deve ter no seu desenvolvimento.
A ideia primordial na indicação do uso de FTM na medicina humana não é substituir medicamentos registrados e já comercializados, mas sim 
HASENCLEVER, L. et al. A Pesquisa indústria de fitoterápicos brasileira: de campo. desafios e oportunidades. Ciência \& Saúde Coletiva, São Paulo, v. 22, n. 8, p. 2259-2269, jan./2017.
ANDRADE, S. A. L. D. et al. Revisão de Fitoterápicos da relação nacional de teor descritivo medicamentos essenciais no Brasil. Revista Cubana de Plantas qualitativa.
Discutir e analisar os

desafios

do indicam que os principais

desenvolvimento

da desafios são, na pesquisa, a

indústria de plantas regulamentação da lei de medicinais e de acesso ao patrimônio genético fitoterápicos no Brasil.

e, na produção, a
harmonização

regulamentação em toda a cadeia produtiva da indústria de plantas medicinais e fitoterápicos. A morosidade da implantação das políticas públicas voltadas para a indústria mostra um retrocesso tanto das atividades produtivas com fitoterápicos, quanto das atividades de pesquisa com plantas medicinais no período.

Realizar uma revisão

Verificou-se que existem sobre os medicamentos inúmeros artigos científicos fitoterápicos da Relação relacionado à temática e Nacional de principalmente informações Medicamentos 
Medicinales, São Paulo, v. 22, n. I, jan./2017.

LEITE, et al. Fitoterapia e o uso indiscriminado do chá de Cannabis sativa. III SIMPÓSIO $\mathrm{DE}$ ASSISTÊNCIA FARMACÊUTICA, São Camilo, v. revistas I, n. I, p. I-I, dez./2017. científicas.

Utilizou-se pesquisa em livros específicos,

$$
\begin{aligned}
& \text { indicações } \\
& \text { apresentações, com } \\
& \text { embasamento técnico- } \\
& \text { científico, criando assim } \\
& \text { um material de fácil } \\
& \text { entendimento para os } \\
& \text { profissionais da saúde. }
\end{aligned}
$$$$
\text { Essenciais com suas fitoterápicos presentes na }
$$$$
\text { e RENAME. }
$$
Abordar

sobre a

O uso do chá de maconha importância dos pode ser prejudicial à saúde, e fitoterápicos, o uso causar tontura, náuseas e indiscriminado do chá sonolência. Os pacientes que de maconha e suas fazem uso controlado do vantagens

e CBD podem apresentar desvantagens. reações adversas como vermelhidão nos olhos, sensação de estar "aéreo", o que é esperado, podendo também apresentar os efeitos mais severos como mal estar, incluindo cefaleia.

REIS, L. A. M. et al. Saberes Revisão populares sobre a automedicação: a crítica da influência dos saberes populares no contexto cultural da prática da automedicação com incorreto de medicamentos fitoterápicos e aumentou de $15 \%$ para $30 \%$, estabelecer condutas que sendo que $7 \%$ correspondiam resultem no controle da a crianças. Outro fator automedicação como encontrado foi a prática popular. automedicação como predisponente a dependência medicamentosa, além de causar o mascaramento de sintomas comprometendo 
ALEXANDRE,

R.F.A.;

Pesquisa

Farm Bonaerense, v.24, n.2, p.310-314, fev./2014.

REZENDE, H. A. D; COCCO, M. I. M. A utilização de fitoterapia no cotidiano de uma população rural. descritiva exploratória. Revista da Escola de Enfermagem da USP, São Paulo, v. 36, n. 3, p. 282-288, set./2013. Disponível em: https://doi.org/10.1590/Soo8062342002000300011 .
Demonstrar

eficácia sobre

medicamentos

Fitoterápicos elaborados

com

Alcachofra,

Castanha-da-Índia,

Ginseng e Maracujá

diagnósticos e tratamentos,
podendo, também, ser
indutores à
bacteriana
alergias.

A fitoterapia baseada em evidências enfatiza a necessidade da avaliação crítica das informações sobre medicamentos fitoterápicos. Esta revisão bibliográfica avaliou e sistematizou as melhores evidências externas obtidas na literatura sobre a eficácia e a segurança dos medicamentos fitoterápicos elaborados com alcachofra, castanha-da-índia, ginseng e maracujá. As evidências são fracas para justificar o uso clínico da alcachofra no tratamento $\quad \mathrm{da}$ hipercolesterolemia, indicando a necessidade da condução de novos estudos.

Estudar o uso da Das plantas conhecidas fitoterapia, em uma pelos entrevistados foram população da zona rural citados 106 nomes diferentes, no interior de MG; destas, algumas se repetiram identificar as plantas e inúmeras foram citadas utilizadas com maior apenas uma vez. Das plantas frequência e formas de utilizadas pelos entrevistados uso e comparar os seus foram referidos sessenta efeitos com aqueles nomes. As plantas mais descritos na citadas foram: hortelã, poejo, 
literatura.

FRANÇA,

Everaldo;

Revisão

Buscou-se

VASCONCELLOS,

Alexandre bibliográfica.

Guimarães. Patentes de fitoterápicos

no Brasil: uma análise do andamento

dos pedidos no período de 1995-2017.

Cadernos de Ciência \& Tecnologia,

Brasília, v. 35, n. 3, p. 329-359,

set./dez. 2018.

\begin{abstract}
carqueja, erva doce, erva cidreira, boldo, folha de laranjeira, limão, camomila, folha de café, folha de cana, cabelo de milho, eucalipto, alecrim, arnica, assapeixe, capim santo, chapéu-de couro, folha de lima, folha de abacate, gravatá.
\end{abstract}

ocompanhar 876 pedidos de patente
depósitos de pedidos de
patentes de fitoterápicos

acompanhar os

Verifica-se que $59,2 \%$ dos patentes.

\section{DISCUSSÃO}

De acordo com Andrade, et al (2017) o fitoterápico é uma preparação farmacêutica padronizada contendo um ou mais extratos de partes de plantas. Portanto, os medicamentos fitoterápicos são produtos industrializados e amplamente comercializados em países desenvolvidos e em desenvolvimento.

Hasenclever, et al (2017) apontam que como quaisquer outros medicamentos, esses medicamentos devem ser comprovados como seguros e eficazes perante a agência reguladora antes 
de entrar no mercado consumidor, e podem ter se originado do conhecimento geral sobre as propriedades medicinais das plantas.

De acordo com Klein, et al (2019), as propriedades curativas das ervas são atribuídas às substâncias ativas presentes no todo ou em parte da planta e são obtidas na forma de extratos totais ou extratos processados. Portanto, na maioria dos casos, os componentes químicos responsáveis pelos efeitos farmacológicos dos medicamentos fitoterápicos no mercado farmacêutico brasileiro são desconhecidos.

De acordo com a Resolução RDC no 17 (24 de fevereiro de 200o), os fitoterápicos são produtos obtidos por meio de processos tecnicamente adequados, utilizando-se como princípios ativos apenas matérias-primas vegetais, que possuem efeitos preventivos e terapêuticos. Caracteriza-se pela compreensão da eficácia e dos riscos da sua utilização, bem como da reprodutibilidade e estabilidade da sua qualidade (LEITE, et al, 2017).

Rezende e Cocco (2013) afirmam que as ervas não são consideradas como contendo substâncias ativas isoladas de qualquer origem, ou seus ingredientes combinados com extratos vegetais. Portanto, de acordo com a ANVISA (2000), a definição de fitoterápico é a seguinte: Droga vegetal: planta ou parte dela, após ser coletada, estabilizada e seca, completa, raspada ou triturada; Matérias-primas vegetais: plantas medicinais frescas, droga vegetal ou seus derivados, que podem existir na forma de extratos, latas, ceras, óleos fixos e óleos voláteis e princípios ativos: substâncias ou seus grupos com características químicas, cujos efeitos farmacológicos são conhecidos, e são totais ou parcialmente responsáveis pelos efeitos terapêuticos das ervas.

Os fitoterápicos são produzidos a partir de um único material derivado de planta, considerado muito simples, quando há mais de um material vegetal são considerados complexos (compostos). Para se ter produtos fitoterápicos, é necessário entender o conhecimento dos vegetais usados para compor uma determinada fórmula (REIS, et al, 2018).

O fitoterápico refere-se a medicamentos cujos princípios ativos terapêuticos são apenas plantas ou derivados de plantas, não podendo incluir em sua composição substâncias ativas isoladas de qualquer origem, nem ser combinada com extratos vegetais. Para França e Vasconcellos (2018) os fitoterápicos não são fitofármacos, são fármacos (compostos com atividade terapêutica) extraídos de vegetais ou seus derivados. 
De acordo com a definição da Organização Mundial de Saúde, os medicamentos vegetais contêm partes de plantas ou materiais vegetais no seu estado original ou processado como princípios ativos, bem como certos excipientes, nomeadamente solventes, diluentes ou conservantes. Uma característica importante dos fitoterápicos é que geralmente não apresentam efeitos farmacológicos imediatos ou fortes, seus princípios ativos são responsáveis pelos efeitos farmacológicos (desconhecidos) e não são utilizados para tratamento de emergência. Outras características da fitoterapia são sua ampla gama de usos terapêuticos e ampla aceitação (ALEXANDRE, GARCIA E SIMÕES, 2014).

A combinação com substâncias ativas quimicamente definidas ou componentes isolados não é considerada medicamento à base de plantas. Ao contrário da medicina moderna, a fitoterapia é frequentemente usada para tratar doenças crônicas. Segundo Virgílio e Marques (2014), os fitoterápicos são normalmente comercializados na forma líquida, sólida (extrato seco e pó) ou em formulação padronizada de formulação viscosa e são feitos por maceração, percolação ou destilação (óleo volátil). .

De acordo com Oshiro (2016) para produzir o extrato líquido, utiliza-se etanol, água ou uma mistura de etanol e água. No processo de extração de matérias-primas, extratos sólidos ou em pó são preparados por evaporação e em comparação com as drogas sintéticas, existem algumas diferenças entre os fitoterápicos, entre elas: os princípios ativos geralmente são desconhecidos; a padronização, a estabilidade e o controle de qualidade são possíveis, mas não fáceis; o uso empírico na medicina popular é uma característica muito importante; têm uma vasta gama de utilizações terapêuticas e são adequadas para o tratamento crónico, sendo os seus preços geralmente inferiores aos das drogas sintéticas.

Segundo Hasenclever, et al (2017) o recente ressurgimento do interesse público em medicamentos fitoterápicos foi atribuído a vários fatores, alguns dos quais incluem (i) várias alegações sobre a eficácia de medicamentos vegetais, (ii) preferência dos consumidores por terapias naturais e um maior interesse em alternativas medicamentos, (iii) crença errônea de que os produtos fitoterápicos são superiores aos produtos manufaturados, (iv) insatisfação com os resultados dos farmacêuticos ortodoxos e a crença de que os medicamentos fitoterápicos podem ser eficazes no tratamento de certas doenças onde as terapias e medicamentos convencionais 
foram comprovados ser ineficaz ou inadequado, (v) alto custo e efeitos colaterais da maioria dos medicamentos modernos, (vi) melhorias na qualidade, eficácia e segurança dos medicamentos fitoterápicos com o desenvolvimento da ciência e tecnologia, (vii) crença dos pacientes de que seus os médicos não identificaram adequadamente o problema; daí a sensação de que os remédios à base de ervas são outra opção e (viii) um movimento em direção à automedicação.

A crescente utilização de ervas para automedicação por pacientes ou indivíduos também é atribuída a uma série de outras razões, como (i) os pacientes se sentirem desconfortáveis em discutir seus problemas médicos e temer a falta de confidencialidade no manuseio de suas informações de saúde, (ii) ) medo de possíveis diagnósticos errados e tratamento incorreto por pacientes com sintomas inespecíficos ou mal-estar geral, e (iii) falta de tempo para consultar um médico; este é geralmente um motivo pelo qual a visita anterior não rendeu nenhuma experiência positiva (ANDRADE, et al, 2017).

Além disso, a liberdade de escolha do médico pelos pacientes também incentiva a utilização de tratamentos alternativos e remédios fitoterápicos, embora muitos selecionem medicamentos fitoterápicos a partir de uma abordagem dedutiva com base em informações anedóticas, ou seja, "funcionou para meu amigo ou parente" (KLEIN, et al, 2019).

Da mesma forma, por causa da influência da religião e do maior nível de consciência espiritual, muitos indivíduos tendem a estar cada vez mais dispostos a aceitar o valor terapêutico de um tratamento baseado na fé ou intuição ao invés do raciocínio científico. Segundo Rezende e Cocco (2013) os medicamentos fitoterápicos, portanto, tornam-se particularmente atraentes quando a capacidade natural do corpo para a auto reparação, em condições adequadas, é enfatizada.

Além de todos esses fatores mencionados acima, as estratégias de marketing e os esforços de vários fabricantes de medicamentos fitoterápicos e seus representantes de vendas projetaram seriamente esses produtos para um destaque maior. Vários anúncios na mídia de massa, incluindo programas de televisão e rádio, aumentaram significativamente a consciência dos consumidores e deram aos produtos à base de plantas respeitabilidade e credibilidade indevidas (FRANÇA E VASCONCELLOS, 2018).

Esses anúncios são apresentados com cuidado para atrair as diferentes faixas etárias de pessoas que existem na sociedade. Para Reis, et al (2018) as crianças são incentivadas a usar ervas para seus 
valores nutricionais para facilitar o crescimento e desenvolvimento normais ou saudáveis; os jovens, por seus efeitos eufóricos, fornecem ingredientes essenciais para ajudá-los a lidar com o estresse diário e para prevenir ou retardar o início do envelhecimento; idosos, por seus efeitos antienvelhecimento ou rejuvenescedores, e mulheres, por seus efeitos adelgaçantes e intensificadores da beleza.

Segundo Alexandre, Garcia e Simões (2014) na maioria dos países, os medicamentos fitoterápicos e produtos relacionados são introduzidos no mercado sem qualquer segurança obrigatória ou avaliação toxicológica. Muitos desses países também carecem de maquinários eficazes para regulamentar as práticas de fabricação e os padrões de qualidade.

Apesar da percepção positiva dos pacientes sobre o uso de medicamentos fitoterápicos e da alegada satisfação com os resultados terapêuticos, juntamente com sua decepção com os medicamentos alopáticos ou ortodoxos convencionais em termos de eficácia e / ou segurança, o problema da segurança dos remédios fitoterápicos continua sendo uma grande preocupação (VIRGÍLIO E MARQUES, 2014).

A percepção geral de que os remédios ou medicamentos fitoterápicos são muito seguros e desprovidos de efeitos adversos não é apenas falsa, mas também enganosa. Segundo Oshiro (2016) as ervas demonstraram ser capazes de produzir uma ampla gama de reações indesejáveis ou adversas, algumas das quais são capazes de causar ferimentos graves, condições de risco de vida e até a morte. Numerosos e irrefutáveis casos de envenenamento foram relatados na literatura.

Recentemente, Andrade, et al (2017) relataram uma associação entre o uso de fitoterápicos tradicionais e o desenvolvimento de fibrose hepática entre os participantes do estudo em Uganda. Vários medicamentos fitoterápicos chineses e outros medicamentos fitoterápicos de diferentes partes do mundo também foram implicados em casos de envenenamento. Foi demonstrado que muitos deles contêm compostos tóxicos que são capazes de reagir com macromoléculas celulares, incluindo DNA, causando toxicidade celular e / ou genotoxicidade.

\section{CONSIDERAÇÕES FINAIS}

A fitoterapia é bem conhecida desde o início e muitas pessoas insistem em usar esse recurso porque, com o tempo, os produtos naturais ganharam reputação por supostamente não causarem 
danos. Porém, mesmo quando se trata de produtos naturais, o excesso e a deficiência podem causar desequilíbrio no organismo, por isso deve ser usado com cautela. $\mathrm{O}$ uso irracional de drogas é um dos problemas de saúde global mais importantes e a situação é pior no domínio dos medicamentos fitoterápicos. As intervenções para combater o uso irracional de medicamentos fitoterápicos e a promoção de uma abordagem mais racional requerem motivação e adesão a diretrizes clínicas rígidas por parte dos profissionais e conscientização do público em geral. Devido ao mal uso, tornou-se obrigatório que os medicamentos fitoterápicos sejam cobertos em todos os países do mundo por uma estrutura regulatória de medicamentos para garantir que estejam em conformidade com os padrões exigidos de segurança, qualidade e eficácia.

\section{REFERÊNCIAS}

ALEXANDRE, R.F.A.; GARCIA, F.N.; SIMÕES, C.M.O. Fitoterapia baseada em evidências. Parte 2. Medicamentos fitoterápicos elaborados com alcachofra, castanha-da-índia, ginseng e maracujá. Acta Farm Bonaerense, v.24, n.2, p.310-314, fev./2014. Acesso em: 23 jan. 2021. ALMEIDA, Maria Zélia. Plantas Medicinais [online]. 3. ed. Salvador: EDUFBA, 2013, 221 p.

ISBN 978- 85-232-1216-2. Available from SciELO Books. Disponível em: 〈http://books.scielo.org/id/xf7vy/pdf/almeida-9788523212162.pdf > Acesso em: I5 jan. 2021.

ANDRADE, S. A. L. D. et al. Fitoterápicos da relação nacional de medicamentos essenciais no Brasil. Revista Cubana de Plantas Medicinales, São Paulo, v. 22, n. I, jan./2017. Acesso em: 23 jan. 2021.

CARVAlHO, Ana C. B.; BALBINO, Evelin E.; MACIEL, Artur. Et al. Situação do registro de medicamentos fitoterápicos no Brasil. Rev. Bras. Farmacogn, 2008. Disponível em: https://www.scielo.br/pdf/rbfar/vi8n2/28.pdf. Acessado em: 23 jan. 2021.

COELHO, Ketellen Mayara e JUNIOR, Hilton Lopes. Fitoterapia Racional: Riscos Da Automedicação e Terapia Alternativa. III Ciclo Científico da Faculdade São Paulo - FSP, Rev. Saberes, Rolim de Moura, vol. 3, n. Esp. jul./dez., p. 35-44, 2015. ISSN: 2358-0909. jan./2015. Đisponível_em: https://facsaopaulo.edu.br/wpcontent/uploads/sites/i6/2018/o5/ed3especial/4.pdf. Acesso em: is jan. 2021. 
FERNANDES, Tania Maria. A ciência nas plantas medicinais: temas e sujeitos do debate atual. In: Plantas medicinais: memória da ciência no Brasil [online]. Rio de Janeiro: FIOCRUZ, 2004, p.I6I-220. ISBN:978-85-754I-348-7.Available from SciELO Books. Disponível em: http://books.scielo.org/id/bg6yw/pdf/fernandes-9788575413487-05.pdf. Acesso em: is jan. 202I.

FRANÇA, Everaldo; VASCONCELLOS, Alexandre Guimarães. Patentes de fitoterápicos no Brasil: uma análise do andamento dos pedidos no período de 1995-2017. Cadernos de Ciência \& Tecnologia, Brasília, v. 35, n. 3, p. 329-359, set./dez. 2018. Acesso em: 23 jan. 2021.

HASENCLEVER, L. et al. A indústria de fitoterápicos brasileira: desafios e oportunidades. Ciência \& Saúde Coletiva, São Paulo, v. 22, n. 8, p. 2259-2269, jan./2017. Acesso em: 23 jan. 2021.

KLEIN, T. et al. Fitoterápicos: um mercado promissor. Revista de Ciências Farmacêuticas Básica e Aplicada, Maringá, v. 30, n. 2, p. 24I-248, jan./2019. Acesso em: 23 jan. 2021.

LEITE et al. FITOTERAPIA E O USO INDISCRIMINADO DO CHÁ DE CANNABIS SATIVA. III SIMPÓSIO DE ASSISTÊNCIA FARMACÊUTICA, São Camilo, dez./2oi7. Acesso em: 23 jan. 2021.

MACEDO, Jussara Alice Beleza. Plantas medicinais e fitoterápicos na atenção primária à saúde: contribuição para profissionais prescritores. Monografia (Especialização) - Instituto de Tecnologia em Fármacos, - Farmanguinhos, Pós-graduação em Gestão da Inovação de Medicamentos da Biodiversidade na modalidade EAD, Rio de Janeiro, p. 58. 2016. Acesso em: is jan. 2021.

MINISTÉRIO DA SAÚDE. A Fitoterapia no SUS e o Programa de Pesquisas de Plantas Medicinais da Central de Medicamentos. Brasília, v. I, n. I, p. 5-290, mar./2016. Disponível em: https://bvsms.saude.gov.br/bvs/publicacoes/fitoterapia_no_sus.pdf. Acesso em: I5 jan. 202I.

ROSSATO, Angela Erna et al. Fitoterapia racional: aspectos taxonômicos, agroecológicos, etnobotânicos e terapêuticos. Volume I. Florianópolis: Diretoria da Imprensa Oficial e Editora de Santa Catarina (DIOESC), 2013. Acesso em: is jan. 2021.

OSHIRO, Mariana Cardoso. A evolução do registro e prescrição de fitoterápicos no 
Brasil sob a perspectiva legal e sanitária. Revista visa em debate: sociedade, ciência e tecnologia, Curitiba, v. 4, n. 2, p. I16-122, mar./2016. Disponível em: 10.22239/2317-269X.00790. Acesso em: is jan. 202I.

SCHOABA, Anna Karenina. Uso de fitoterapia: Matricaria Recutita e Arnica Montana no Tratamento da dor causadas por inflamação. Monografia apresentada ao curso de graduação em Farmácia, Ariquemes, v. 7 , n. 3, p. I0-34, jan./2018. Disponível em: http://repositorio.faema.edu.br/bitstream/123456789/2161/r/USO\%2oDE\%2oFITOTERAPIA.p df. Acesso em: is jan. 202I.

SILVA, Roberto Pereira d.; ALMEIDA, Aila Kaliana Pereira d. e ROCHA, Francisco Angelo Gurgel d. Os riscos em potencial do uso indiscriminado de plantas medicinais. CONNEPI, São Paulo, p. 7, abr./2014. Acesso em: 15 jan. 2021.

SOUZA, Brayon Wevely Alves de. et al. A importância da atenção farmacêutica e farmácia clínica no uso racional de medicamentos fitoterápicos. Revista de Iniciação Científica e Extensão (REICEN) - Anais do I Congresso de Ciências Farmacêuticas do Centro-Oeste, Brasília, v. 2 n. Esp.I. jan./2019. Disponível em: https://revistasfacesa.senaaires.com.br/index.php/iniciacaocientifica/article/view/225/165. Acesso em: 15 jan. 2021.

VIRGÍlIO, L.J. E MARQUES, L.C. Avaliação dos efeitos da Resolução RDC i7 sobre fitoterápicos de registros antigos. Revista Brasileira de Farmacognosia, Maringá, v. 4, n.I, p. IooII3, dez/2014. Disponível em: https://doi.org/ro.1590/Soro2-695X2004000300002. Acesso em: is jan. 2021.

REIS, L. A. M. et al. Saberes populares sobre a automedicação: a utilização indiscriminada de fitoterápicos. SENABS, São Paulo, v.ı, n.I, dez/2018. Acesso em: 23 jan. 2021.

REZENDE, H. A. D; COCCO, M. I. M. A utilização de fitoterapia no cotidiano de uma população rural. Revista da Escola de Enfermagem da USP, São Paulo, v. 36, n. 3, p. 282-288, set./2013. Disponível em: https://doi.org/ro.159o/Soo8o-62342002000300orr. Acesso em: 24 jan. 202I. 